\title{
Ambivalência(s) da adolescência e a importância do médico de família: um relato de caso
}

Ana Rita Magalhães, ${ }^{1}$ Joana Montenegro Penetra, ${ }^{2}$ Ana Catarina Domingues, ${ }^{3}$ Ana Letra, ${ }^{3}$ Maria Glória Neto, ${ }^{4}$ Nicoleta Martins ${ }^{5}$

\section{RESUMO}

Introdução: O médico de família (MF), além de estar apto a abordar as problemáticas mais prevalentes da adolescência, deve ainda promover a participação ativa e responsável do adolescente nas questões de saúde, fundamentando a sua ação numa intervenção individualizada e na confidencialidade. A consciência da orientação sexual, no caso da homossexualidade, surge normalmente no período da adolescência, podendo envolver um período de confusão e dúvida. A discriminação e os estereótipos associados ainda marcam muito quem se vê confrontado com a sua orientação sexual.

Descrição do caso: Sexo masculino, 16 anos, consulta de vigilância de saúde a pedido da mãe que, dias antes, procura os elementos da equipa por noção de isolamento, tristeza e receio de problema psicológico grave com o filho. Durante abordagem conhecida pelo acrónimo HEEADSSS, sozinho, surge a dúvida sobre a própria sexualidade, admitindo pensar ser homossexual, com inúmeros receios, ambivalências e vergonha acerca deste assunto, que o têm levado a afastar-se da família, grupo de amigos e colegas. As dúvidas relacionadas com o futuro escolar e profissional também o deixam preocupado, sentindo-se sozinho num mundo com o qual não se identifica. Escuta ativa e confidencialidade, desmistificação de algumas temáticas e disponibilidade para consultas, assim como encaminhamento para consulta de psicologia fazem parte do plano conjunto centrado no adolescente, que apresenta franca melhoria do humor e motivação.

Comentário: As dúvidas relativas à orientação sexual podem ser devastadoras no período da adolescência, condicionando isolamento, autoculpabilização e vergonha. O MF ocupa uma posição que favorece a deteção precoce e esclarecimento das questões relacionadas com a sexualidade, permitindo assim um crescimento e desenvolvimento saudáveis, em termos físicos, psicológicos e sociais.

Palavras-chave: Método clínico centrado no paciente; Orientação sexual; Adolescência.

\section{INTRODUÇÃO}

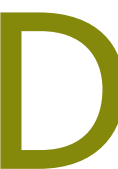
e acordo com a Organização Mundial da Saúde, a adolescência considera o grupo etário entre os 10 e os 19 anos, tratando-se de um processo biopsicossocial que pode ser despoletado antes do início da puberdade e durar para além do termo do crescimento. São várias as transformações que ocorrem nesta fase: as físicas, que incluem

1. Médica de Família. USF Coimbra Norte, ACeS Baixo Mondego.

2. Médica de Família. USF As Gândras, ACeS Baixo Mondego.

3. Médica Interna de Medicina Geral e Familiar. USF Topázio, Coimbra.

4. Médica de Família. USF Topázio, Coimbra.

5. Enfermeira. USF Topázio, Coimbra. o crescimento somático e a puberdade; as psíquicas, com o aumento das capacidades cognitivas; e as sociais, com a aquisição de novos papéis e responsabilidades. ${ }^{1} \mathrm{O}$ desenvolvimento acontece a vários níveis, com a formação de uma identidade pessoal e de grupo, a exploração de novas relações e a procura de uma identidade sexual. De facto, é nesta idade que o adolescente reflete sobre si próprio e sobre a sua sexualidade, sobre as emoções e sobre o desejo que sente em relação aos outros, que podem ser do mesmo sexo, de outro sexo ou de ambos os sexos. Também as perspetivas e decisões iminentes relativas ao futuro profissional podem ser geradoras de dúvidas, medos e receios, 
associadas à separação emocional dos pais e à defesa de valores morais baseados em obrigações e modelos. É, assim, uma fase vulnerável a pressões externas face ao desenvolvimento, com maior frequência de comportamentos de risco e de exploração e experimentação física e social. ${ }^{2-4}$

A homossexualidade e a bissexualidade são variantes da sexualidade humana, como o é também a heterossexualidade. A consciência de que se é homossexual pode surgir neste período, sendo a forma de o descobrir diferente de pessoa para pessoa e podendo envolver um período de confusão e de dúvidas. ${ }^{5}$ A discriminação e estereótipos associados à homossexualidade $\mathrm{e}$ bissexualidade ainda marcam muito quem se vê confrontado com a sua orientação sexual. Assim, a aprendizagem da sexualidade leva muitas vezes a um estado de confronto interno no próprio sujeito, no meio de muita ansiedade, de transformações intra e interpessoais, que culminam na integração da identidade sexual. $^{5-6}$

No atendimento a adolescentes, para além da acessibilidade facilitada e da flexibilidade no modelo do atendimento, a privacidade, a confidencialidade, o exercício do consentimento livre e esclarecido e a participação ativa do próprio adolescente, constituem princípios que devem presidir a todas as iniciativas tomadas. Os adolescentes são muito diferentes entre si, nomeadamente no ritmo de maturação e no modo como vivenciam as várias transformações, pelo que a intervenção terá de ser adaptada a cada caso específico. ${ }^{7}$

$\mathrm{Na}$ entrevista com o adolescente, a abordagem dos aspetos psicossociais adquire uma particular importância e permite conhecer melhor, quer pontos fortes quer fatores de vulnerabilidade pessoal, face aos diferentes contextos de vida. Para ajudar o profissional de saúde neste conhecimento, Henry Bearman desenvolveu o acrónimo HEADS (1972), que tem vindo a ser aperfeiçoado até aos dias de hoje em que comummente se utiliza o HEEADSSS. ${ }^{8}$ Este modelo permite encontrar problemas não verbalizados espontaneamente e clarificar fatores protetores e de risco:

$\mathbf{H}$ - Home (casa, família);

E - Education e employment (escola e emprego);

E - Eating (alimentação);

A - Activities (atividades desportivas e de lazer);

D - Drugs (consumos, adição);
S - Sexuality (sexualidade);

S - Suicide (depressão, suicídio, humor);

S - Safety (segurança, acidentes, violência).

O presente caso clínico pretende exemplificar a importância da relação empática, personalizada e centralizada nos cuidados ao adolescente, nomeadamente quanto às dúvidas relativas à sua orientação sexual, causadoras de sofrimento e angústia. A gestão das expectativas, o envolvimento de outros profissionais de saúde e a confiança conquistadas, permitiram ao MF ajudar este adolescente a ultrapassar as ambivalências percecionadas. Por outro lado, salienta ainda a dualidade e os desafios de manter a privacidade e o sigilo profissional relativamente ao menor, sendo também MF de outros elementos do agregado familiar.

\section{DESCRIÇÃO DO CASO}

Duarte (nome fictício), 16 anos, caucasiano, católico praticante, natural e residente no concelho de Coimbra, estudante do $11^{\circ}$ ano. Inserido em família nuclear em fase V do Ciclo de Duvall, classe socioeconómica de Graffar média. Antecedentes pessoais de síndroma do intestino irritável diagnosticado em 2010 e apendicite gangrenada em 2012 (Figura 1). PNV atualizado sem vacinas extra-plano.

Em maio de 2016, a mãe solicita consulta para o Duarte por noção de isolamento, tristeza e mudanças comportamentais por parte do filho (discurso ríspido, ausência de afetos e afastamento gradual dos elementos do agregado familiar e irmã), receando que este esteja deprimido ou a ser alvo de problema que não verbaliza com família. Agendada consulta dentro de cinco dias, estando acompanhado pela mãe que, a seu pedido, permanece na sala de espera durante a consulta. Após consulta de enfermagem e avaliação de crescimento e desenvolvimento pubertário, são explanados os receios da sua mãe, justificação o agendamento da consulta. Foi aplicado ao longo da consulta, e de forma informal, o questionário HEEADSSS:

$\mathrm{H}$ - Relação muito boa com mãe e irmã, sentindo-se desapoiado e afastado desta última desde que saiu de casa para viver com companheiro. Mãe católica praticante, muito preocupada com os filhos, pai militar da GNR, muito rígido no que diz respeito a regras e rotinas, pouco falador ou afetuoso, sem abertura ao diálogo, mas não violento. Aplicado Apgar Familiar de 


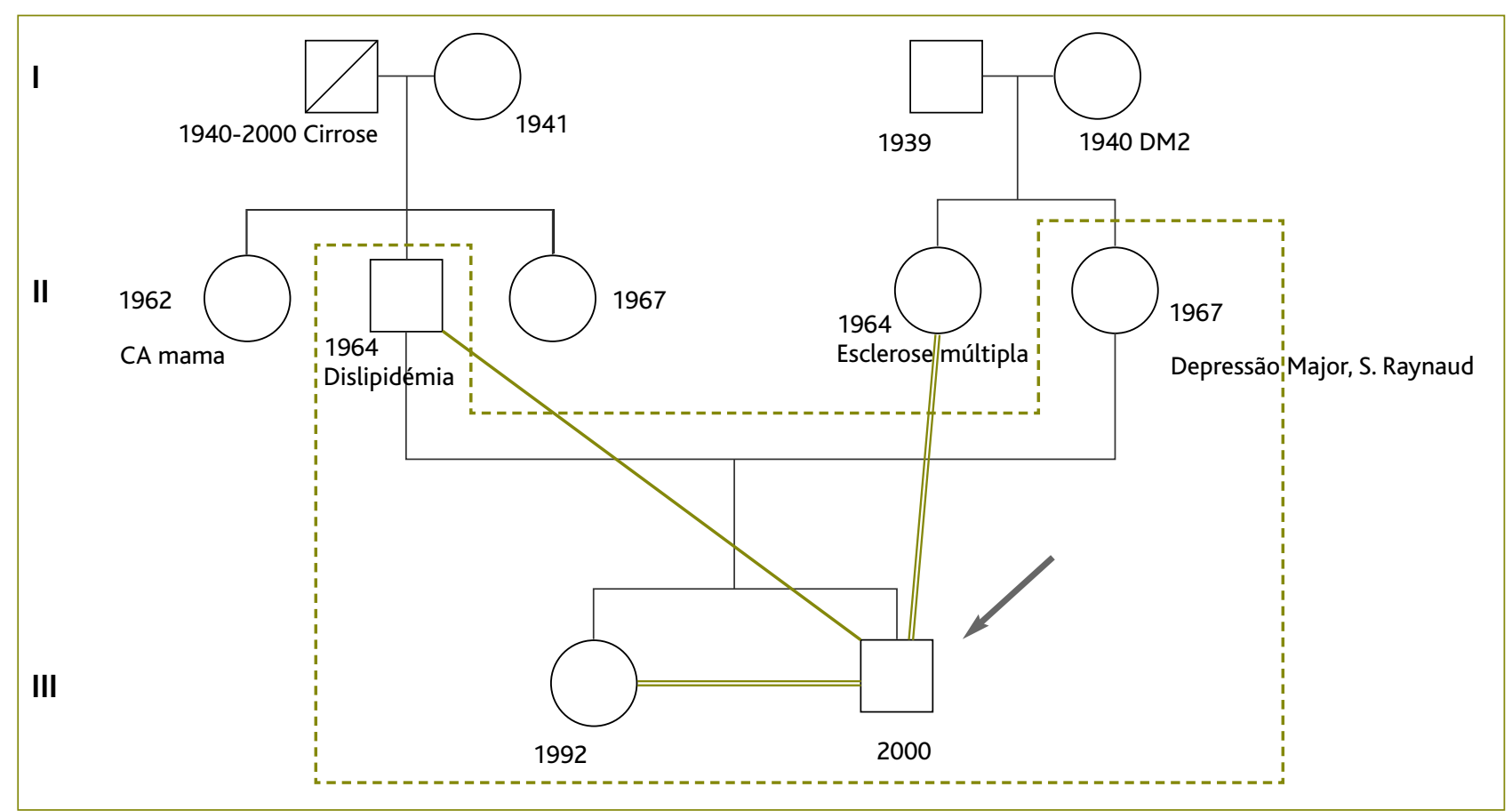

Figura 1. Genograma e psicofigura de Mitchell realizado em agosto 2016 (USF Topázio).

Smilkstein, revelando uma família funcional - 7 pontos (Quadro I).

E, E, A, D - Encontra-se numa fase em que não sente afinidade com o grupo de amigos, nomeadamente por divergências quanto aos gostos musicais, passatempos, saídas noturnas e consumos, confessando sentir pressão social para a ingestão de bebidas alcoólicas e hábitos tabágicos, negando consumos. Tem vindo a sentir isso desde há alguns meses, o que o tem levado a afastar-se e a sentir-se culpado por essa mesma atitude, pois sempre se sentiu bem com o grupo. Enfrenta com dificuldade a pergunta acerca das expectativas profissionais futuras, não sabendo o que responder; por um lado, o sonho era ser comissário de bordo mas, por outro, sente necessidade de frequentar o ensino superior de modo a corresponder às expectativas que diz sentir por parte da família. Gosta de design, mas pensa não ser o curso que os pais idealizaram para ele e, também de arquitetura, mas receia não conseguir média suficiente. Considera-se muito perfecionista, sendo bom aluno, mas frequentemente insatisfeito apesar de todas as conquistas. Mantém as atividades desportivas de natação, contudo a exigência associada às obrigações escolares, em que nunca falhou, levou a que abandonasse a alta competição, referindo este afastamento com mágoa. Participa ainda no coro da igreja local, no qual se sente bem.

S - De forma espontânea durante a consulta verbaliza dúvidas quanto à sua orientação sexual, referindo ser homossexual, embora nunca tenha tido nenhuma relação amorosa quer com raparigas quer com rapazes. Menciona então que há alguns meses se apercebeu de forma clara da sua orientação sexual, após se ter sentido atraído por um colega de turma, o que o perturba, pois sempre pensou que iria gostar de raparigas. Esta descoberta levou-o a isolar-se da família e amigos. "Não entendo porque não posso gostar de raparigas, era tudo mais fácil" (sic). Tem dúvidas quanto à própria religião e receia a reação da família, principalmente dos pais. Quanto à irmã, anteriormente a sua principal confidente, verbaliza não ter coragem para lhe contar. Tem amiga próxima, que também não sabe.

S, S-Apesar de todas as dúvidas, ambivalências e dificuldades com que se tem vindo a debater, do isolamento e atitude introspetiva, nega choro fácil, anedonia, anorexia, insónia ou ideação suicida. 


\section{QUADRO I. Apgar familiar de Smilkstein}

Estou satisfeito com a ajuda que recebo da minha família, sempre que alguma coisa me preocupa.

Estou satisfeito pela forma como a minha família discute assuntos de interesse comum e compartilha comigo a solução do problema.

Acho que a minha família concorda com o meu desejo de encetar novas atividades ou de modificar o meu estilo de vida.

Estou satisfeito com o modo como a minha família manifesta a sua afeição e reage aos meus sentimentos, como irritação, pesar e amor.

Estou satisfeito com o tempo que passo com a minha família.

Total

Ao exame objetivo salientam-se nas biometrias, peso, estatura e IMC nos percentis 50-85 e tensão arterial no percentil < 90 . Relativamente à observação clínica, de destacar o aspeto cuidado com que se apresenta, a boa higiene dentária e ausência de cáries, a acuidade visual de acordo com a escala de Snellen de 10/10 para ambos os olhos e um estadio pubertário de Tanner IV (P IV; G IV). Do exame do estado mental, nada a destacar.

Ao longo da consulta, o Duarte insiste em pedir para não contar aos pais, sendo-lhe explicado calmamente que a consulta é sigilosa. Relativamente ao plano conjunto, partilhado e com envolvência do Duarte, é sugerido encaminhamento para consulta de psicologia, que prontamente aceita, bem como a exprimir as suas dúvidas e receios a amiga ou irmã, tentando a reaproximação aos amigos, embora não cedendo a pressões relativas aos consumos nocivos. Explica-se a importância da tranquilização dos pais, em particular da mãe, com maior ênfase no diálogo em família e na expressão de afetos. É agendada nova consulta.

Optou-se por envolver a mãe no final da consulta e tranquilizá-la, esclarecendo que se trata do período da adolescência composto por dúvidas e receios, ambivalências e que nada de mais grave ou preocupante se passa com o Duarte.

Regressa em julho de 2016, tem frequentado as consultas de psicologia, sentindo-se mais tranquilo quanto ao futuro profissional uma vez que está a realizar testes de orientação vocacional, mantendo, contudo, sentimentos ambivalentes relativos à orientação sexual. De forma conjunta são pesquisados os contactos da In- tervenção Lésbica, Gay, Bissexual e Transgénero de Portugal (ILGA), da Sexualidade em Linha e do site da Associação para o Planeamento da Família (APF), reforçando que não deve sentir-se diferente. Insiste-se nas vantagens de desabafar com amigo de confiança ou irmã, explicando que a conversa com os pais deve existir na altura que pensar ser apropriada para o efeito. Tem-se tentado reaproximar progressivamente dos amigos. Refere melhoria da relação com os pais, têm jantado em família diariamente e passado algum tempo ao fim-de-semana a passear com a mãe.

Regressa em agosto de 2016 com a mãe e irmã, que permanecem no exterior. Tem mantido e aproveitado as consultas com psicólogo. Menciona que os testes de orientação vocacional reforçaram a ideia de arquitetura e ele próprio se sente bem quando pensa nessa opção, mantendo as dúvidas quanto à sua capacidade de obter notas suficientemente altas nos exames. Acerca da sexualidade, após ter contado à irmã, esta tem tido um papel de suporte e de apoio. No entanto, tem a sensação de que esta pensa tratar-se apenas de uma fase de experimentação (mesmo que nunca tenha sido verbalizado pela própria). Tem mantido reaproximação aos amigos e programado atividades juntos. Vai mudar de escola, o que o deixa igualmente apreensivo e entusiasmado, já que poucos colegas se manterão. Tem falado muito mais com a mãe, no sentido minimizar a sua preocupação com ele, descansando-a e tentando programar tempo de qualidade com esta.

Em setembro de 2016, após ter sido informada pelo próprio da orientação sexual do filho, é realizada consulta à mãe do Duarte, confessando dificuldade em li- 
dar com a notícia. Sabe que o marido não pode, para já, saber. Não entende a orientação sexual do filho; contudo, não a questiona e tem-no apoiado. Receia que não seja só uma fase e que a família terá de lidar com o assunto aos poucos. É-lhe explicado que a sexualidade não é uma escolha e que geralmente está definida desde prematuramente. Reforça-se o papel de suporte que deve ter perante o filho, uma vez que este sofre com as dúvidas dele próprio e que a família deve ser o elo de apoio numa sociedade que ainda discrimina.

O Duarte volta em janeiro de 2017, sorridente e afável. Tem-se adaptado à escola de forma positiva, estando inserido num novo grupo de colegas, de quem gosta e com o qual se identifica, mantendo ainda assim a ligação aos amigos prévios. Verbaliza sentir-se bem, tem lido muito sobre orientação sexual e mantém contacto regular com a ILGA sempre que surgem dúvidas. O psicólogo tem tido um papel muito importante, pretendendo manter as consultas. Menciona alívio extremo após ter falado com mãe sobre o assunto, embora esteja consciente da dificuldade que tem em lidar com a situação devido às crenças religiosas e à conhecida posição não favorável do pai quanto ao assunto (manifestada em situações em que o assunto homossexualidade é genericamente comentado no seio familiar). Não quer que este saiba enquanto não for independente financeiramente do mesmo; contudo, sente-se mal pela posição em que a mãe se encontra em relação a ambos. Tem tido boas notas e espera conseguir entrar em arquitetura. É fornecido o $e$-mail de forma a ser possível esclarecer dúvidas e manter o contacto, após o Duarte ter acordado não serem necessárias mais consultas presenciais.

\section{COMENTÁRIO}

Este caso exemplifica duas situações comuns na prática do médico de família: por um lado, é o médico de todo o agregado familiar e, por outro, tem um papel preponderante na saúde física e mental de um indivíduo.

A adolescência é, por excelência, um período rico em dúvidas, receios e ambivalências, contudo, normais. O papel do MF é, sem dúvida, importante nesta fase da vida do indivíduo, na vigilância do crescimento e desenvolvimento, mas também na promoção da saúde e na prevenção da doença.
Neste caso, o seu papel foi essencial, quer na tranquilização da figura materna quer na ajuda prestada ao adolescente, sem julgamentos ou imposições. No entanto, na sua prática clínica, e sobretudo ao lidar com esta faixa etária, é crucial garantir a confidencialidade das informações prestadas. De facto, o sigilo médico foi uma preocupação verbalizada pelo indivíduo logo na primeira consulta, tendo sido necessário realçar que o mesmo nunca estaria em causa para que a relação médico-utente se pudesse estabelecer. Apesar de o MF se encontrar emocionalmente afastado da situação, a empatia permite-lhe compreender as dúvidas e receios de ambos os utentes, tendo um papel muito importante em estimular o entendimento mútuo, alertando ambos os elementos para as necessidades do outro, mesmo sem quebra do sigilo. Assim, apesar da apreensão do Duarte, foi também necessário ter em conta a preocupação da mãe, também utente, e a necessitar também ela do seu MF. No entanto, a tranquilização da mesma foi apenas conseguida com a ajuda do próprio Duarte, não só no momento da consulta, mas também em casa, com uma progressiva reaproximação e preocupação em passar mais tempo de qualidade com a família. Adicionalmente, no apoio prestado ao adolescente foi essencial incentivá-lo a procurar amparo nas suas relações, de forma a sentir-se acompanhado no seu meio.

Este caso, para além de ser um grande desafio durante a consulta, obrigou igualmente a um trabalho de casa por parte do clínico, levando-o à pesquisa de outros meios de auxílio, como instituições de apoio que pudessem servir de suporte ao adolescente.

A multidisciplinaridade entre o clínico e o psicólogo foi essencial, resultando na formação de uma equipa complementar capaz de fazer o adolescente enfrentar as suas preocupações. Os desafios no seguimento a este adolescente mantêm-se, sendo importante a atuação em várias áreas preventivas, como são os casos da eventual vacinação contra o vírus do papiloma humano ou da educação para a saúde no que diz respeito à prevenção de doenças sexualmente transmissíveis.

\section{REFERÊNCIAS BIBLIOGRÁFICAS}

1. Mclntyre P. Adolescent friendly health services: an agenda for change. Geneva: World Helth Organization; 2002.

2. Prazeres V. Saúde dos adolescentes: princípios orientadores. Lisboa: Direção-Geral da Saúde; 1998. ISBN 9729425612 
3. Direção-Geral da Saúde. Programa nacional de saúde infantil e juvenil: norma n. ${ }^{\circ}$ 010/2013, de 31/05/2013. Lisboa: DGS; 2013.

4. Neinstein LS, Gordon CM, Katzman DK, Rosen DS, Woods ER. Adolescent health care: a practical guide. 5th ed. Wolters Kluwer/Lippincott Williams \& Wilkins; 2008. ISBN 9780781792561

5. Associação para o Planeamento da Família. Identidade e orientação sexual [homepage]. Lisboa: APF. Available from: http://www.apf.pt/sexualidade/identidade-e-orientacao-sexual

6. Pereira H, Leal IP. A identidade (homo)sexual e os seus determinantes: implicações para a saúde. Anál Psicológica. 2005;23(3):315-22.

7. Sociedade Portuguesa de Pediatria. Requisitos para o atendimento ao adolescente: consenso da Secção de Medicina do Adolescente da Sociedade Portuguesa de Pediatria. Lisboa: SPP; 2005.
8. Goldenring JM, Rosen DS. Getting into adolescent heads: an essential update. Contemp Pediatr. 2004;21(1):64-90.

\section{CONFLITO DE INTERESSES}

Os autores declaram não ter quaisquer conflitos de interesse.

\author{
ENDEREÇO PARA CORRESPONDÊNCIA \\ Ana Rita Magalhães \\ E-mail: anaritamag@gmail.com \\ https://orcid.org/0000-0001-5579-9276
}

Recebido em 11-05-2018

Aceite para publicação em 30-07-2019

\section{ABSTRACT}

\section{AMBIVALENCE(S) OF ADOLESCENCE AND THE ROLE OF THE FAMILY PHYSICIAN: A CASE REPORT}

Introduction: The family physician (FF) besides being able to address the most prevalent problems of adolescence, should also promote the active and responsible participation of the adolescence in health matters, based on their individualized intervention and confidentiality. The awareness of sexual orientation in the case of homosexuality usually arises during adolescence and it might involve a period of confusion and doubt. Discrimination and associated stereotypes still mark a lot of those who are confronted with their sexual orientation.

Case report: Male, 16 years, presented to the consult after some concern of his mother for isolation, sadness, and fear of serious psychological problems with her child. During the well known HEEADSSS acronym assessment, the question arises about his own sexuality admitting to being homosexual, with innumerable fears, ambivalences, and shame about this, that have led him to move away from the family, group of friends and colleagues. Doubts about the future in school and profession also leave him worried and feeling alone in a world he does not identify himself with. Active listening and confidentiality, the demystification of some themes and availability for consultations, as well as referral to psychologists are part of the joint plan, which is maintained, with frank improvement.

Commentary: Doubts about sexual orientation can be devastating in the teenage years, conditioning isolation, self-blame, and shame. The FF occupies a privileged position in the early detection and clarification of issues related to sexuality, thus allowing a healthy growth, physical, psychological and socially.

Keywords: Patient-centered clinical method; Sexual orientation; Adolescence. 